\title{
Sentidos e significados da Educação: transformações e desafios
}

\author{
Senses and meanings of education: changes and challenges
}

\section{Editor}

Alexandre Anselmo Guilherme PUCRS, RS, Brasil

\section{Editor Assistente}

Cibele Cheron

PUCRS, RS, Brasil

\section{Editores Associados}

Bruno Antonio Picoli

Universidade Federal da Fronteira Sul, Chapecó, SC, Brasil

Pricila Kohls dos Santos

Universidade Católica de Brasília,

Brasília, DF, Brasil

Renato de Oliveira Brito

Universidade Católica de Brasilia,

Brasilia, DF, Brasil

Elisa Ustarroz

PUCRS, Porto Alegre, RS, Brasil

\section{ISSN 2179-8435}

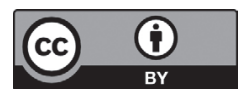

Este artigo está licenciado sob forma de uma licença Creative Commons Atribuição 4.0 Internacional, que permite uso irrestrito, distribuiçăo e reprodução seja corretamente citada.

\section{Alexandre Anselmo Guilherme ${ }^{1}$
Cibele Cheron ${ }^{1}{ }^{1}$ \\ Alexandre Anselmo Guilherme ${ }^{1}{ }^{1}$
Cibele Cheron (1) ${ }^{1}$ \\ ${ }^{1}$ Pontifícia Universidade Católica do Rio Grande do Sul, Porto Alegre, RS, Brasil.}

A celeridade das transformações e mudanças experimentadas pelas sociedades nos últimos decênios estende seus efeitos em todas as dimensões da vida humana. No campo da Educação essas transformações assumem diversos sentidos, implicando, simultaneamente, em novas possibilidades e em grandes desafios. Nesse cenário, as identidades e as atuações de docentes, estudantes e da própria escola são questionadas e ressignificadas. Abordam-se, assim, aspectos democráticos da Educação, fator de dinamização das estruturas que se concretiza no ato inovador do indivíduo. Esse, habilitado a atuar no contexto societário em que vive, torna-se capaz de reorganizar o seu comportamento e contribuir para a reestruturação da sociedade a partir das suas experiências, análise e avaliação crítica. Por essa ótica, indivíduo e sociedade são vistos em um contexto dinâmico de constantes mudanças.

Questionando o paradigma instrucional, a escola se vê impelida a converter-se em plataforma de transformações sociais, o que demanda sua reinvenção para atender a novas exigências, demandas e papeis. A gestão de seu espaço passa a ser desafiada por uma pluralidade de responsabilidades socioeducativas que transbordam as funções tradicionais da disciplina e da transmissão de conhecimento em uma nova lógica de inclusão, socialização e cidadania (NÓVOA, 2005).

Assim, regras de comportamento essenciais para o convívio em comunidade passam a fazer parte do contexto escolar, simultaneamente a esgarçamentos e rupturas do tecido social, explicitados por conflitos que podem escalonar até a ocorrência de episódios de violência. Nesse contexto, entra em xeque a cultura disciplinar, compondo uma perspectiva social na qual se imbricam questões pedagógicas, estruturais e educativas (QUARESMA, 2010). 
No contexto presente, em que o capitalismo global demanda a crescente flexibilização dos processos produtivos, Ilan Gur-Ze'ev (2002) enfatiza as reconfigurações que comprometem alguns dos pressupostos da práxis pedagógica, tais quais o desaparecimento dos mercados físicos e a consequente quebra da identificação entre mercadoria e sua representação, entre economia e cultura. A Educação, nesse cenário, assume a dinâmica de uma jornada interminável, sem caminhos preestabelecidos ou horizontes alcançáveis. Igualmente, assume-se que o ser humano não é objeto de idealização, e nem pode ser tomado como algo pronto. O ser humano está em contínua construção e, nessa premissa, ser humano significa tornar-se humano, conquistar-se, apoderar-se de si. A consciência do "eu", simultânea à consciência do "nós", torna o ser humano um sujeito responsável, ético, individual e social, necessariamente em interação com o outro. Interação essa que nem sempre será harmônica ou equilibrada, pois a sociedade é plena de interesses e valores divergentes.

Esses questionamentos estão presentes nesta edição da revista Educação Por Escrito, trazendo artigos convergentes à proposta de divulgar e fomentar a produção de conhecimentos no campo da Educação desde uma perspectiva interdisciplinar e engajada, espaço para compartilhamento de saberes e formação de pesquisadores.

No primeiro artigo, Fernanda Martins questiona a centralidade atribuída aos diretores pelo atual modelo de gestão, ao que associa processos de erosão da gestão democrática e, em contraponto, discute as possibilidades de uma liderança escolar multifacetada.

O segundo artigo, assinado por Anelise Volkveiss, Vanessa Mendes de Lima, José Luís Schifino Ferraro e Maurivan Güntzel Ramos, traz as percepções que um grupo de professores de Educação Básica em formação continuada e outro de estudantes têm acerca das dificuldades em se promover o protagonismo estudantil na escola.

Ramofly Bicalho e Marizete Andrade Silva, no terceiro artigo, caracterizam a Educação do Campo no Espírito Santo, apresentando as experiências educacionais que se constituem como alternativa de resistência dos camponeses ao padrão de desenvolvimento estabelecido pelo capital, em uma estreita relação com a materialização das lutas travadas pelos movimentos sociais e pela formação do educador nas escolas do campo, enquanto espaços de produção crítica, autônoma e emancipadora do conhecimento.

Karine Gutheil Franzen e Elisiane Machado Lunardi, no quarto artigo, apresenta reflexões sobre os desafios na construção do Projeto Político Pedagógico da Educação Infantil da rede municipal de Ensino de Toropi-RS, propondo uma discussão dialógica com gestores e professores para discussão do PPP da Educação Infantil.

Ederson Luiz Locatelli, autor do quinto artigo, busca compreender de que forma as alunas do curso de Pedagogia PARFOR se apropriam das tecnologias digitais por meio do engajamento e do desenvolvimento de projetos de aprendizagem na perspectiva do hibridismo e da multimodalidade proporcionando a reinvenção da sua prática docente. 
No sexto artigo, Érica Santana Silveira, Bianca Resende Campos Silveira, Otília Maria Alves da Nóbrega e Alberto Dantas observam o sentido do desenvolvimento profissional para pós-graduandos das áreas de Educação e Turismo, cursistas de Pós-graduação em uma Universidade pública brasileira, vinculando o desenvolvimento profissional ao conhecimento da sua profissão e, por conseguinte, à constituição das suas identidades profissionais, valorização, união e busca pela reafirmação dos seus direitos e deveres.

O desenvolvimento profissional também é objeto do sétimo artigo, no qual Késsia Mileny de Paulo Moura, Marie Jane Soares de Carvalho e Renata Fischer da Silveira Kroeff discutem o que consideramos autoprodução docente nos escritos de portfólios de aprendizagem no contexto do estágio em docência em um curso de pedagogia a partir da teoria da autopoiese.

O oitavo artigo, assinado por Ernandes Rodrigues do Nascimento, Maria Auxiliadora Padilha, Cristiane Lucia da Silva e Fábio Leandro Melo Ramo dos Anjos empregam a teoria da autopoiese para discutir a noção de autoprodução docente a partir dos escritos de portfólios de aprendizagem no contexto do estágio em docência em um curso de Pedagogia.

No mesmo sentido, as dificuldades enfrentadas pelos docentes são analisadas por Heraldo Simões Ferreira, Maria Adriana Borges dos Santos, Silvia Maria Nóbrega-Therrien, Vanessa Carvalho Forte no nono artigo, examinando fatores que favorecem e dificultam práticas inovadoras na formação do professor supervisor no Programa Pibid, no Ceará.

No $10^{\circ}$ artigo, Francisco Nunes Sousa Moura, Shirliane de Araújo Sousa e Jones Baroni Ferreira Menezes examinam a concepção dos docentes dos cursos de licenciatura da cidade de Crateús, também no Ceará, quanto à importância das tecnologias de informação e comunicação para formação dos alunos de licenciatura.

O $11^{\circ}$ artigo, os autores Amanda Cristina Tedesco Piovezan e Leandro Daros Gama propõem o exemplo de uma sequência didática, na qual equipes de estudantes são convidadas a resolver problemas e a responder questões interdisciplinares, envolvendo astronomia e matemática.

No 12ㅇartigo, que igualmente aborda o ensino da matemática, Márcia Jussara Hepp Rehfeldt, Sabrina Monteiro, Marli Teresinha Quartieri, Ieda Maria Giongo e Marisa Cristina Gorgen narram resultados decorrentes das atividades de Investigação Matemática envolvendo o cálculo de diagonais, a fim de buscar formas desafiadoras para trabalhar Matemática em sala de aula, onde o professor atuasse como articulador dos processos de ensino e aprendizagem, e o aluno, como protagonista na produção do seu conhecimento.

O penúltimo artigo é assinado por Paulo Augusto Tamanini e Maria do Socorro Souza, e engloba um mapeamento das produções acadêmicas que abordam o uso das novas tecnologias no ensino de História, revelando o que está sendo produzido nos últimos anos sobre esse tema, buscando identificar tanto as tendências investigativas a ele concernentes como as principais contribuições e lacunas nesse campo teórico. 
O 15ㅇe último artigo, Liliane Gontan Timm Della Méa, Adriana Moreira da Rocha Veiga, Doris Pires Vargas Bolzan dedicam-se a compreender origens da Educação Superior no Brasil, destacando a sua expansão e regulação, para situar o surgimento da Pós-Graduação e de sua avaliação pela Coordenação de Aperfeiçoamento de Pessoal de Nível Superior (Capes).

Parabenizamos as autoras e os autores, e desejamos a todas e todos uma proveitosa e agradável leitura.

\section{Referências}

GUR-ZE’EV, I. É possível uma educação crítica no ciberespaço? Comunicações, Piracicaba, v. 9, n. 1, p. 72-98, 2002. Disponível em: https://www.metodista.br/revistas/revistas-unimep/index.php/comunicacoes/article/view/1569/982. Acesso em: 3 jul. 2018. https://doi.org/10.15600/2238-121X/comunicacoes.v9n1p72-98

NÓVOA. A. Evidentemente: Histórias da educação. Porto: Edições Asa, 2005.

QUARESMA, L. Interação e indisciplina na escola. In: ABRANTES, P. (org.). Tendências e controvérsias em sociologia da educação. Lisboa: Mundos Sociais, 2010. p. 159-171.

Recebido em: 17/12/2019.

Aprovado em: 17/12/2019.

Publicado em: 31/12/2019.

\section{Endereço para correspondência}

Pontifícia Universidade Católica do Rio Grande do Sul

Av. Ipiranga, 6681, Prédio 8, Sala 304.13

90619-900, Porto Alegre, RS, Brasil

\section{Autores:}

Alexandre Anselmo Guilherme

Doutor em Educação. Professor Pesquisador PPGEdu/PPGP (PUCRS). Coordenador do Grupo de Pesquisas em Educação e Violência (GruPEV).

Reader da Catedra UNESCO de Juventude, Educacao e Sociedade (UCB - Brasília).

Orcid: https://orcid.org/0000-0003-4578-1894

E-mail: alexandre.guilherme@pucrs.br

Cibele Cheron

Pós-doutorado em Educação (PUCRS). Doutora em Ciência Política (UFRGS). Mestre em Ciências Sociais (PUCRS). Bacharel em Ciências Jurídicas e Sociais (UFRGS). Professora Universitária da PUCRS. Pesquisadora associada ao Grupo de Estudos do Sul Global (UFABC) e ao Núcleo Interdisciplinar de Estudos sobre Mulher e Gênero (UFRGS). Mediadora judicial certificada (TJRS).

Orcid: https://orcid.org/0000-0003-3501-5248

E-mail: cibele.cheron@pucrs.edu.br 